\title{
Falhar melhor: novos apon- tamentos sobre a palavra salvação
}

Pedro Eiras

Universidade do Porto - ILC

Resumo: Deriva sobre os sentidos do verbo salvar. Tentativa de conceber um uso paradoxal, não-económico, da palavra - em que salvar se aproxime de perder, saber perder, saber aceitar a efemeridade do mundo.

Palavras-chave: salvação, perda, aceitação, arte

Abstract: Drift on the meanings of the verb to save. Attempt to conceive a paradoxical, noneconomic use of the word - in which saving approaches loss, knowing how to lose, knowing how to accept the ephemerality of the world.

Keywords: salvation, loss, acceptance, art

Tentar outra vez. Falhar outra vez. Falhar melhor. Samuel Beckett

Em tempos, tentei escrever sobre a palavra "salvar".

Tentei, por várias vezes, em diversos textos, compreender o que significa a palavra, e como se usa, e por que razão tantos dos seus usos me desagradam. Encontrei essa palavra na poesia e no cinema, na teologia e na filosofia; não sei se tinha sempre o mesmo significado, as mesmas implicações. Escrevi várias vezes sobre ela, não sei se alguma vez consegui explicar a mim próprio toda a sua ambiguidade. Talvez o mal 
esteja nos limites do meu pensamento, da minha escrita. Ou talvez a própria palavra "salvar" conduza a impasses, a uma insidiosa contradição; talvez seja tão plural e dividida que recuse um qualquer simples comentário.

Mas que fazer - senão perguntar de novo, falhar de novo, falhar um pouco melhor?

A palavra "salvar" usa-se em diversos jogos de linguagem (Wittgenstein). 0 verbo ganha significados diferentes em expressões como, por exemplo, "salvar uma vida”, "salvar a alma de um pecador", "salvar uma empresa da falência”, "salvar uma revolução”, “salvar o capitalismo”. É muito diferente "salvar o mundo” e "salvar alguém de si próprio". "Salvar um refugiado, salvar uma minoria”; "salvar a face"; "salvar um documento no computador". "Salvo seja”, "salvo erro”. Em inglês, to save é também gravar um documento, ou poupar dinheiro. Em francês, se sauver pode ser fugir. Uma salva de tiros é uma forma de saudação.

Talvez a polissemia da palavra nunca possa ser inteiramente eliminada: talvez nunca se possa saber ao certo em que sentido(s) alguém, falando, usa a palavra "salvar”. Talvez, na leitura ou audição desse vocábulo, na hermenêutica de um texto que o usa, seja preciso hesitar muito mais, ler mais "de/vagar", como sugere Herberto Helder (2009: 128), compreender que existem aí significados contraditórios latentes - e talvez convocá-los em simultâneo. Não é certo que uma palavra, mesmo num dado contexto (e em que texto poderíamos esgotar a descrição do contexto?), tenha um só significado. Talvez seja preciso renunciar já a qualquer definição exaustiva, aceitar que a mesma palavra terá inevitavelmente uma significação plural, de contornos imprecisos; talvez seja preciso fazer o elogio da dúvida e da polissemia.

Neste texto, porém, tento sistematizar alguns usos. Distinguirei, nomeadamente, “salvar vidas” de "salvar almas”, ou seja, as acepções material e espiritual do mesmo verbo, as linguagens da medicina, do direito, da política, e a da teologia.

Na verdade, mesmo a expressão "salvar vidas” é usada em acepções divergentes. Por um lado, pode designar o trabalho das organizações e dos voluntários que resgatam migrantes africanos do Mediterrâneo, em perigo de afogamento iminente; de todos aqueles que defendem tribos índias do desflorestamento da Amazónia; de quem luta pela emancipação de minorias, pela justiça para presos políticos, pelo direito à existência de populações perseguidas; de quem combate o aquecimento global. Neste sentido, "salvar" é a tarefa central, urgente, inadiável de várias formas de activismo, e implica uma transformação radical do mundo, uma revisão da noção de justiça, uma revolução conceptual que interrogue conceitos como identidade, alteridade, direito, homo sacer (Agamben) e grievable life (Butler). Salvar, neste sentido, implica transformar o mundo.

Por outro lado, vale a pena interrogarmos o sentido da expressão "salvar vidas" no imaginário dos filmes-catástrofe: perante a ameaça de terramotos, maremotos, erupções vulcânicas, colisões com meteoros, o protagonista do filme (quase sempre um homem, branco, americano, casado ou separado, com dois filhos - uma criança e 
um adolescente...) deve "salvar a humanidade". Assim, o herói protege da catástrofe um grupo maior ou menor de indivíduos (incluindo mulheres, crianças, uma família negra, etc.), podendo eventualmente sacrificar-se para bem da colectividade. Certo é que, no fim do filme-catástrofe segundo Hollywood, não só se cumpre o trabalho de luto pelos mortos e a humanidade continua a existir, como ainda as instituições, os rituais, os hábitos, os valores permanecem intactos: o mundo pós-catástrofe está temporariamente um pouco mais arruinado, mas na prática idêntico àquilo que era. Mais: o herói como salvador da humanidade fortalece aqueles valores. Salvar, neste sentido, implica manter o mundo tal como ele é.

Ou seja, a expressão "salvar vidas” admite já duas leituras contraditórias conforme "salvar" seja revolucionar o mundo até ao irreconhecível ou conservá-lo exactamente igual a si próprio. 0 mais desafiante dos verbos pode ser também o mais complacente, e decerto é difícil estabelecer critérios rigorosos para afirmar em qual das duas acepções o verbo "salvar" é usado de cada vez: decerto convém manter sob suspeita uma palavra tão dúplice, incerta no seu uso, cheia de implícitos.

Mas a este jogo de uma ambiguidade latente na expressão "salvar vidas" (salvar uma comunidade, uma civilização, uma cultura, uma ideologia) importa acrescentar os paradoxos presentes na expressão "salvar almas”, agora em clave teológica. Penso na matriz apocalíptica: no fim dos tempos, os mortos ressuscitam e são julgados; os justos não sofrem segunda morte, mas é-lhes concedido viverem com Deus; os injustos, porém, são condenados ao sofrimento eterno. Assim, o diabo, a besta e o falso profeta são "lançado[s] para dentro do lago de fogo e enxofre" e "torturados de dia e de noite pelos séculos dos séculos" (Ap 20:IO); quanto aos injustos, cujos nomes não aparecem no livro da vida, são igualmente "atirado[s] para o lago de fogo" (20:15). Os justos, porém, nomeados naquele livro, habitam eternamente a Jerusalém descida dos céus, além do tempo: "E já não haverá noite e não precisarão de luz da candeia e de luz solar, porque o Senhor Deus iluminá-los-á; e reinarão pelos séculos dos séculos” (21:5). A História é cancelada, e o Juízo Final não admite recurso: salvação e danação são definitivas.

Podemos encontrar neste modelo de salvação a promessa de uma revolução absoluta, a utopia de uma justiça plena, universal, definitiva: a salvação dos justos consistiria na reinvenção radical do mundo, da comunidade. Mesmo na tradição histórica das esperanças milenaristas, o Apocalipse sustentou muitas vezes projectos de revolução, a reinvenção das comunidades e da justiça. Mas, regressando à sugestão de uma ambiguidade insanável, essa mesma utopia da salvação pode equacionada como mera experiência de um ressentimento vivido pelos primeiros cristãos, perseguidos pelos imperadores romanos. D. H. Lawrence relê o Apocalipse como um livro marcado pela "imperecível vontade de poder" (1993: 21), manifestada através de uma "apoteose do homem fraco" (31). Ou seja, sob a aparente revelação espiritual do texto, haveria apenas, segundo Lawrence, um programa político para atribuir à comunidade 
uma embriagante sensação de poder, uma capacidade de destruir: "A religião dos fortes pregava a renúncia e o amor; a religião dos fracos pregava: abaixo os fortes e os poderosos, e que os pobres sejam glorificados. Como no mundo há sempre mais gente fraca do que forte, o segundo tipo de cristianismo é que triunfou e triunfará" (18). Nesta leitura, o cancelamento do tempo, o Juízo Final, a Jerusalém celeste são apenas formas, afinal muito profanas, de confirmar o poder de um grupo, maneiras de salvar um mundo ameaçado, ou seja, de o conservar.

Se tão contrária a si própria é a ideia de salvar, se o verbo pode ter significados tão diferentes, e porque talvez nenhum contexto seja suficientemente claro e completo para esclarecer por inteiro em que sentido se deve entender a palavra, se à salvação como acto revolucionário pode sempre subjazer um fundo de conservação, se salvar tanto significa transformar como preservar, tanto a surpresa do outro como a confirmação do mesmo, então como se pode, como se deve compreender este conceito?

Como compreender, por exemplo, o fim da narrativa "A viagem”, de Sophia de Mello Breyner Andresen, em Contos Exemplares? Recordo: uma mulher e um homem viajam, de carro, atravessando uma paisagem de serras, campos, aldeias, rios; não se esclarece de onde vêm, para onde vão. E aos poucos, inexplicavelmente, tudo vai desaparecendo - fontes, casas, o cavador a quem chegaram a pedir direcções, o carro, a própria estrada. 0 homem, de repente, também já não está ali. Despojada de tudo, "agarrada a ervas e raízes", a mulher compreendeu "que agora era ela que ia cair no abismo":

Viu que, quando as raízes se rompessem, não se poderia agarrar a nada, nem mesmo a si própria. Pois era ela própria o que ela agora ia perder.

[...]

Então virou a cara para o outro lado do abismo. Tentou ver através da escuridão. Mas só se via escuridão. Ela, porém, pensou:

- Do outro lado do abismo está com certeza alguém.

E começou a chamar. (2014: 128-129)

Talvez não se possa, não se deva resolver tudo quanto esta parábola deixa em suspenso - desde os nomes das personagens, a sua origem, o seu destino (a bem dizer, que importam os nomes, as origens, os destinos?), até esta enigmática intuição de que há algo do outro lado do abismo, até ao nome que é chamado (acaso importa qual nome é esse?). Decerto não se pode saber se alguém, do outro lado, responde; e isso importa? Decerto menos do que o acto de chamar.

Eis uma mulher em perigo de perder tudo - e a si própria. 0 conto termina no preciso instante em que ela se pode, ou não, salvar - mas em que sentido devemos entender a palavra? Salvar-se seria recuperar o companheiro, a estrada, o carro, a paisagem; desfazer a própria experiência da perdição, esquecer a angústia de estar 
no "meio da vida" (IO5); recuperar o passado exactamente como foi, e conservá-lo? Ou salvar-se é apenas chamar um nome além do abismo, haja ou não haja resposta?

A propósito da ideia de salvação e do chamamento, lembro-me também de "Pequena história, em versículos, do rapaz e do lobo”, de Daniel Faria, no póstumo O Livro do Joaquim. Conhecemos a matriz desta narrativa: trata-se da história tradicional do rapaz que mente, anunciando o ataque de lobos contra o seu rebanho; mas na versão de Daniel Faria rapidamente se esclarece: mesmo se o rapaz está sozinho e grita "Socorro, que vem lobo!", a verdade é que “O rapaz não troçava de ninguém” (2007: 85). 0 texto deixa bem claro que não há aqui qualquer jogo menor, nem sequer um endereçamento à comunidade humana; o apelo do rapaz tem outra dimensão, menos dizível.

Depois, a pequena fábula termina - ou suspende-se - de modo imprevisto:

7 Mas um dia, estava o rapaz em casa, um lobo veio muito de mansinho - o rapaz nem sabe se o viu ou se gritou - e feriu-o bem no coração.

80 lobo deitou-se, depois, aos pés do rapaz e o rapaz, com a mão em sangue, afagava-lhe devagar o pelo, enquanto que com a cabeça encostada ao seu focinho lhe ia dizendo ao ouvido:

- Socorro, socorro... (ibidem)

Nenhuma simples moralidade ao jeito do conto popular, nenhum castigo do mentiroso para instrução moral dos ouvintes. Antes um enigma que não pretende explicar nem instruir, que não se converte no capital de um conhecimento certo. Pelo contrário, o conto - história, fábula, parábola? - leva a este gesto imprevisível: o rapaz pede socorro ao próprio lobo, ou a um lugar secreto dentro do lobo. Como a mulher em Sophia, não sabemos se receberá alguma ajuda; e suspeitamos agora que não há diferença entre a ameaça e o socorro, o lobo como portador da morte e o lobo como portador da salvação. Sabemos agora que, em Daniel Faria, não importa procurar o socorro fora daquilo que fere mortalmente.

E não é certo que saibamos aqui o que é salvar, e se o rapaz pode ou quer salvar-se, e se aquilo a que apela é também aquilo de onde lhe vem a morte. Ele não resiste a morrer, não luta por conservar uma vida; tem tudo a perder, nada a salvar; e nem sei se espera realmente algum socorro, ele que afaga o pêlo do lobo, o qual por seu turno já terminou o ataque mortal e agora permanece deitado, dócil. É difícil dizer, agora, onde está o perigo, onde a salvação, é difícil articular estas palavras, opô-las. Como no conto de Sophia, não saberemos mais nada: a narrativa termina, elíptica, antes de haver alguma resposta (decerto a resposta não importa nada).

Talvez, nestes textos de Sophia e de Daniel Faria, não haja nada a salvar. E não por mera impotência, não porque o desaparecimento da paisagem é inexorável e o lobo tão poderoso, mas porque a mulher e o rapaz aceitam a ameaça mortal e concentram todas as suas forças no gesto do apelo. Quando o rapaz chama por socorro 
ao lobo, dentro do lobo, através do lobo, ele sabe que não pode recuperar a vida. Não poderíamos estar mais longe do imaginário dos filmes-catástrofe, com a sua defesa do status quo; mas mesmo a ideia de uma Jerusalém celeste, com a sua promessa de eternidade, de revelação infinita, parece demasiado triunfal e ruidosa. 0 socorro que o rapaz pede não tem nada a ver com a recuperação do passado nem com a esperança do futuro. Em rigor, ele parece não pedir nada: nem o tempo, nem a eternidade. Poderemos, nestas circunstâncias, continuar a usar a palavra "salvação”?

Talvez seja preciso redefinir o verbo “salvar”, retirá-lo dos gonzos, pensá-lo num sentido não-económico, muito distante das ideias de conservação, manutenção, guarda, pecúlio, posse. Paradoxalmente, será preciso aproximar o verbo "salvar" de um verbo como "perder" - que deveria parecer o seu oposto. Para realizar este salto conceptual, podemos reler os Evangelhos. Cito frases de Cristo, segundo os quatro testemunhos:

Quem quiser salvar a sua vida perdê-la-á. Mas quem perder a sua vida por minha causa encontrá-la-á. (Mateus 16:25)

Quem quiser salvar a sua vida perdê-la-á. Mas quem perder a sua vida, por minha causa e por causa da boa-nova, salvá-la-á. (Marcos 8:35)

Quem quiser salvar a sua vida perdê-la-á; mas, quem perder a sua vida por minha causa salvá-la-á. (Lucas 9:24)

Quem ama a sua vida, perde-a; e quem odeia a sua vida neste mundo, conservá-la-á na vida eterna. (João 12:25)

O paradoxo destes enunciados é fascinante. Eles dizem que querer salvar a vida é perdê-la; nenhuma Jerusalém terrena, nenhum status permanece. Mas, mais importante, perder a vida é salvá-la: consagrar a vida própria a uma causa justa salva a própria vida. Não importa se Antígona é castigada com a morte: perdida para a vida, ela salva-se ao realizar o gesto justo. Quando o activista defende as minorias perseguidas, ele salva a sua vida, perdendo-a.

Claro que, entre os quatro Evangelhos, o testemunho de João parece mais radical, e decerto provocaria a repulsa de D. H. Lawrence: “odiar a vida neste mundo" pode ser lido como um sinal de ressentimento, numa denúncia de tradição nietzschiana; e a promessa de uma compensação enquanto "vida eterna” parece tornar o gesto do sacrifício menos desinteressado. Em Daniel Faria, antes de pedir socorro ao lobo, o rapaz não começou por odiar a vida; do mesmo modo, no instante em que pede socorro, talvez não espere nenhuma recompensa, tempo reencontrado, Jerusalém etérea. Qualquer expectativa de um ganho introduz a suspeita de um cálculo ou de um ressentimento. 
Importa, em suma, que o gesto seja paradoxalmente gratuito. Sabemos, desde Kant, que um acto moral se define por ser desinteressado, sem recompensa (imanente ou transcendental). Um gesto ético realizado com mira num qualquer proveito deixa imediatamente de ser ético; do mesmo modo, segundo Kant, a moralidade de um acto exige a perspectiva da morte de Deus. Realizar a justiça na expectativa da Jerusalém celeste não é realizar a justiça, mas pretender comprar um lugar na cidade divina (e portanto deixar de merecer esse lugar). Como enfatiza Simone Weil, o justo é aquele que nem se lembra de ter sido justo.

Não há nada a salvar: "salvar" tem de ser um verbo intransitivo. Dito de outro modo, salvar implica aceitar perder a vida; e mesmo essa perda não pode decorrer de um ódio à vida, como em João: é preciso amar a vida profundamente, e mesmo assim aceitar perdê-la.

Como se pode saber perder a vida? E por que razão essa perda das coisas é essencial para as salvar?

No breve ensaio "Transitoriedade”, Sigmund Freud descreve um passeio que deu com um jovem poeta por uma paisagem natural. Embora essa paisagem fosse bela, o poeta parecia desanimado, perturbado pela ideia de que "toda essa beleza estivesse destinada a perecer [...], tal como toda a beleza humana, tudo o que de belo e sublime as pessoas tivessem criado ou pudessem criar”, ou seja, “Tudo o que ele, de outra forma, teria amado ou admirado the parecia perder valor devido à fatal transitoriedade a que estava votado" (1994: 194). Freud comenta:

Esta exigência de eternidade só por si é claramente uma exigência dos nossos desejos e não o resultado de uma reivindicação realista: aquilo que é doloroso também pode ser verdadeiro. [...] Mas contestei a visão pessimista do poeta de que a transitoriedade do belo implicasse a perda do seu valor.

Pelo contrário, implica um aumento! O valor de transitoriedade corresponde a um valor de escassez no tempo. A limitação das possibilidades de usufruto aumenta a sua preciosidade. [...] o valor de tudo o que é belo e perfeito é apenas determinado pelo seu significado para a nossa vida emocional, não necessitando de nos sobreviver e sendo, por isso, independente de uma duração temporal absoluta. (ibidem)

Todos os comentários deste ensaio de Freud costumam enfatizar a data da sua publicação, o ano de 1916, a I Guerra Mundial - ou seja, o pessimismo do jovem poeta é lido como reacção a um cenário de catástrofe; do mesmo modo, a obra de Freud nos anos seguintes - incluindo as intuições sobre o luto, a pulsão de morte, os descontentamentos da civilização - é geralmente lida como resposta ao conflito de dimensões planetárias. A “transitoriedade" referida no texto de 1916 não seria apenas, portanto, o devir natural, observado pela filosofia pelo menos desde Heraclito, mas também uma forma de efemeridade calculada pela própria civilização humana. 
A resposta de Freud parece-me muito lúcida: por um lado, reconhece a necessária efemeridade do mundo, recusando a "exigência de eternidade”, não admitindo, portanto, a expectativa de qualquer Jerusalém celeste; mas, por outro lado, faz derivar daquela mesma efemeridade o valor da existência. 0 investimento amoroso do sujeito depende, assim, do carácter perecível das coisas: ama-se aquilo que se vai perder, e ama-se porque é condição das coisas serem perdidas; ou, mais radicalmente, ama-se a própria perda anunciada nas coisas, a sua fragilidade constitutiva, a raridade do seu surgimento, a sua improbabilidade e o espanto de, apesar de tudo, elas serem. Eis então a proposta de Freud: não exigir o modelo artificial do eterno, mas aceitar (desejar?) o tempo, o devir, a perda. Não é preciso conservar as coisas, é preciso amá-las na condição de coisas que se perdem, coisas sem eternidade.

Nesta senda, exigir a permanência das coisas é estar ressentido (Nietzsche, D. H. Lawrence) contra o devir. Pelo contrário, abre-se aqui a hipótese de uma aceitação densa do acidental, do contingente, das coisas sem a "exigência dos nossos desejos". A este propósito, lembro-me de Stalker, de Andrei Tarkovsky (1979). Claro, não preciso de dizer tudo quanto afasta Tarkovsky de Freud - nomeadamente o salto de fé místico do cineasta, contra o positivismo extremo do psicanalista -; mas a aceitação do mundo em Stalker, a contemplação que não pede qualquer eternidade, o valor atribuído à pequenez das coisas são modos de voltar a pensar a "transitoriedade" freudiana.

Lembro-me do Stalker quando entra na Zona e, depois de despistar os soldados e vigilantes, depois de avançar em silêncio pela linha de caminhos de ferro, se afasta um pouco do Escritor e do Cientista, contempla a vegetação, ajoelha, se deixa cair no chão; os planos em picado ajudam a fundir o corpo na malha de caules, folhas. Ora, não se trata daquele fundo mille fleurs que fascina o observador das tapeçarias $L a$ Dame à la Licorne ou do quadro A Primavera de Botticelli, com a sua miríade de espécies; não se trata do jardim do Éden, eterno e imune à decadência e à morte; nem da Ideia platónica, una e eternamente contemplável. Pelo contrário, o solo em que o Stalker ajoelha dir-se-ia pobre, neutro, como que insignificante; as plantas são selvagens, frágeis, vulneráveis, mortais;

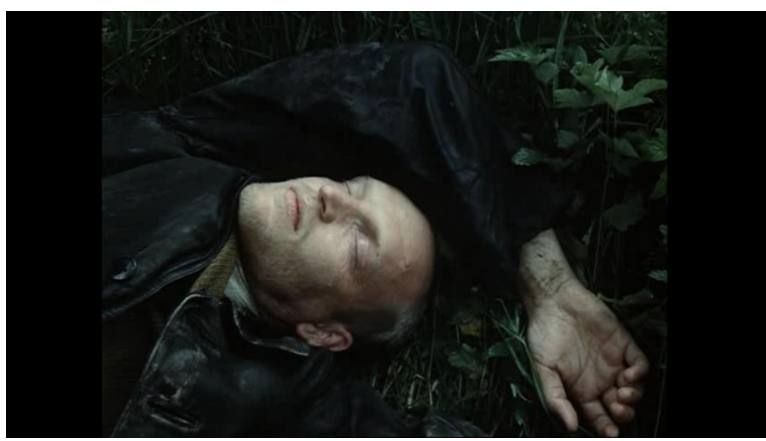


E contudo, ao mesmo tempo, a ambiguidade destas imagens é inesgotável. Numa abordagem inicial, e decerto muito ingénua, devemos ver apenas a pobreza desta paisagem, quase decepcionante para que pudesse esperar, desde o início do filme, um Jardim das Delícias. Porém, não há aqui qualquer disforia. Pelo contrário, quando o Stalker está caído no chão, de olhos fechados, com as mãos e os pulsos sujos com terra, entre ervas e pequenas plantas banais, compreende-se que ele está no paraíso, e que o paraíso é este solo, este húmus. Importa então responder à pergunta: o que há de tão extraordinário nesta paisagem, a ponto de o Stalker se encontrar tão comovido? E a resposta é simples: não há nada de extraordinário nesta paisagem, e tudo nela é extraordinário. Nada se pode salvar nesta paisagem, e tudo está salvo nesta paisagem.

Ainda assim, o Stalker sofrerá a tentação de uma dúvida: esperará dos seus clientes nesta expedição, o Escritor e do Cientista, que peçam o desejo certo na misteriosa câmara dos desejos (tal como, na expedição anterior, esperou o mesmo acto messiânico junto de outros clientes, e na expedição seguinte decerto voltará a esperar). 0 próprio Stalker cede a esta fraqueza: pensa que há um desejo transcendental a pedir, um resgate das coisas, uma alteração da paisagem transitória. Confia-se, inocentemente, a supostos intelectuais, que na hora decisiva não conseguem articular qualquer palavra. Na sua fragilidade magoada, o Stalker não compreende que não é preciso pedir qualquer salvação, porque a Zona - ou a Terra - já está salva. Sobretudo - não compreende que não é preciso aguardar um Messias, que apenas importa ouvir a sua própria mulher, aquela que ama o mundo tal como ele é, aquela que aceita a própria dor.

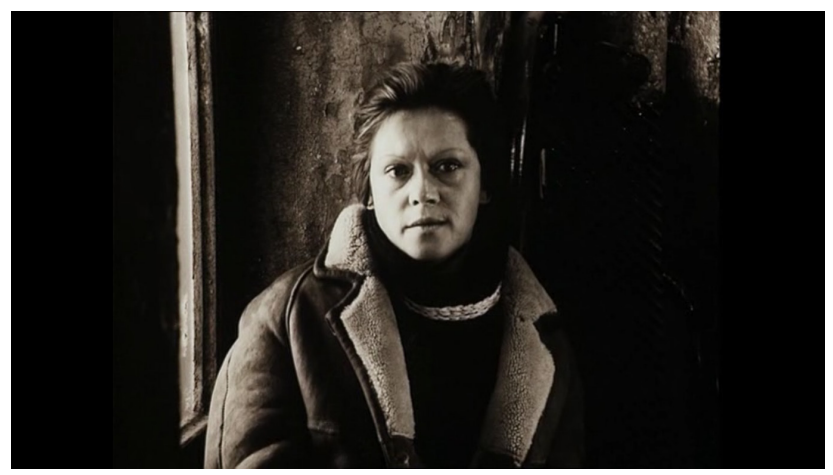

Esta, claro, é apenas uma das leituras possíveis de Stalker. Como já explorei noutro local (Eiras 2012), os filmes de Tarkovsky mantêm em aberto uma pluralidade de abordagens, fornecendo os elementos necessários para interpretações radicalmente opostas; e esse gesto criativo da interpretação é uma tarefa ética a que os espectadores não se podem furtar. Ou seja, o acto do espectador - incluindo as suas intuições, esperanças, 
cepticismos, crenças paradoxais - reflecte os actos das personagens em Stalker, e de resto em todos os filmes de Tarkovsky: ao compreenderem o Escritor e o Cientista, ao seguirem o Stalker, ao ouvirem a sua mulher, os espectadores realizam, eles próprios, o trabalho de crença e descrença que o filme testa. Ao hesitarem perante o último plano de Stalker, ao admitirem que o copo pousado sobre a mesa entra em movimento graças aos poderes da criança ou simplesmente porque a passagem do comboio faz trepidar a casa, ao hesitarem mas também ao decidirem, vez após vez, entre as duas explicações, sem prova conclusiva - falhando, falhando de novo, falhando melhor -, os espectadores atravessam a Zona.

É imprescindível esclarecer um pormenor. Quando a perspectiva de Freud aceita a transitoriedade das coisas, quando a mulher do Stalker aceita o próprio sofrimento da sua vida, importa muitíssimo recusar uma leitura quietista, acomodada ou céptica destes gestos; importa muitíssimo distinguir esta cosmovisão daquele princípio conservador dos filmes-catástrofe que evoquei mais acima.

Os filmes-catástrofe reconhecem uma ameaça radical da civilização, mas apenas para, no fim, resgatar o mundo tal-como-era; o próprio resgate demonstra e realiza essa conservação do mundo. Tudo o que ia mudar radicalmente - afinal permanece igual (com a vantagem / agravante de as relações de poder terem sido testadas, e se tornarem portanto mais fortes; o desfecho do filme sugere que as personagens regressaram à saudável normalidade do quotidiano, e assim naturalizam esse mesmo quotidiano, status quo confundido com uma suposta ordem natural das coisas).

Bem pelo contrário, a aceitação extrema sugerida em Stalker é um gesto difícil, raro, que pede uma extrema consciência do quotidiano, da dor, da ameaça que paira sobre os dias. A mulher do Stalker não tem nenhuma ordem do poder a conservar, nenhum quietismo temeroso a defender. Dialogando com o marido, ela chega a propor ir até à câmara dos desejos; ele mal ouve a proposta, obcecado com a ideia de que a salvação tem de vir de um homem distante; e ela não insiste, porque sabe que, no fundo, ir ou não ir à câmara dos desejos é irrelevante. Aceitar a vida tal como ela é, compreender que não há nada a salvar (mas que tudo já está salvo, mesmo o que é doloroso, mesmo o que é transitório), renunciar à própria câmara dos desejos (que talvez apenas confirmasse um estado de coisas humano): isso, sim, é importante, é fundamental.

Volto a citar Sophia de Mello Breyner Andresen. Já não um dos Contos Exemplares, mas a sua “Arte poética III”, de 1964:

A coisa mais antiga de que me lembro é dum quarto em frente do mar dentro do qual estava, poisada em cima duma mesa, uma maçã enorme e vermelha. Do brilho do mar e do vermelho da maçã erguia-se uma felicidade irrecusável, nua e inteira. Não era nada de fantástico, não era nada de imaginário: era a própria presença do real que eu descobria. Mais tarde a obra de outros artistas veio confirmar a objectividade do meu próprio 
olhar. Em Homero reconheci essa felicidade nua e inteira, esse esplendor da presença das coisas. [...]

Sempre a poesia foi para mim uma perseguição do real. Um poema foi sempre um círculo traçado à roda duma coisa, um círculo onde o pássaro do real fica preso. (2015: 893)

Já não terei tempo para ler neste ensaio, com toda a lentidão necessária, estas linhas luminosas; assinalarei só algumas intuições. Por exemplo: o facto de o quarto, a mesa, a maçã, o próprio mar existirem no tempo. 0 quarto foi construído, e há-de cair; a maçã vai apodrecer, se não for comida; e nem o mar é eterno. Mas que a maçã seja, num determinado instante, "enorme e vermelha” - nada, nem sequer a transitoriedade de tudo, o pode impedir; e então também a felicidade é “irrecusável, nua e inteira”. Logo depois, Sophia esclarece: "Não era nada de fantástico, não era nada de imaginário: era a própria presença do real que eu descobria”. Nada aqui depende uma salvação extraordinária, de um estado de excepção, de um acontecimento miraculoso; nem sequer é preciso chamar além do abismo; ou procurar uma câmara dos desejos perdida no meio da Zona; e muito menos preservar as instituições do mundo e as suas relações de poder. Pura e simplesmente, o "esplendor da presença das coisas" já está nas próprias coisas. Não há nada a salvar.

Termino este ensaio com algumas linhas de Maria Gabriela Llansol, com um episódio relatado no diário Inquérito às Quatro Confidências (1996). Na entrada de 28 de Dezembro de 1995, Llansol recorda um almoço com Vergílio Ferreira:

A última vez que nos vimos foi no restaurante, em Sintra. [...] A refeição fluía mas o Vergílio, no uso da sua mente, estava arrasador. Descria de tudo. "Estamos tramados", dizia. [...] Eu fervia, até que, num impulso, lhe pus uma colher de chá à frente do prato e Ihe disse, como nunca lhe dissera: "Meu Deus, esta colher está agora aqui, e no espaço edénico.” (1996: 142-143)

A mais simples matéria do mundo - uma colher de chá - está aqui e agora, e também, ao mesmo tempo, no espaço edénico. Não é preciso procurar, sugere o texto de Llansol, noutra dimensão espacial ou além do abismo, noutro tempo ou depois do fim dos tempos, não é preciso exigir uma excepção à transitoriedade do mundo. Não é preciso salvar nada, grande ou pequeno, porque as coisas estão salvas no seu próprio acontecimento, ínfimo e inteiro. Estar aqui e agora, eis a tarefa, a difícil tarefa que nos cabe. 


\title{
Notas
}

\begin{abstract}
* Pedro Eiras é Professor de Literatura Portuguesa na Universidade do Porto e Investigador do Instituto de Literatura Comparada Margarida Losa. Desde 2005, publicou diversos livros de ensaios sobre literatura portuguesa dos séculos XX e XXI, estudos interartísticos, questões de ética. Entre os mais recentes: This Is the Way the World Ends (2020), O Riso de Momo - Ensaio sobre Pedro Proença (2018), [...] - Ensaio sobre os mestres (2017), Constelações 2 - Estudos Comparatistas (2016). Entre 2013 e 2018 organizou os Seminários do Fim do Mundo e editou online os libretos Materiais para o Fim do Mundo; em 2020 lançou a sequência Seminários da Salvação do Mundo.
\end{abstract}

\footnotetext{
** Este ensaio foi desenvolvido no âmbito do Programa Estratégico “UIDP/00500/2020”, financiado por Fundos Nacionais através da FCT - Fundação para a Ciência e a Tecnologia.
}

\section{Bibliofilmografia}

Andresen, Sophia de Mello Breyner (2014), Contos Exemplares, Porto, Assírio \& Alvim [1962].

-- (2015), “Arte poética III”, in Obra Poética, Porto, Assírio \& Alvim: 893-894 [1964].

Apocalipse (2017), in Bíblia, vol. Il: Apóstolos, Epístolas, Apocalipse, Lisboa, Quetzal: 555-605.

Beckett, Samuel (1996), Últimos Trabalhos de Samuel Beckett, O Independente / Assírio \& Alvim.

Eiras, Pedro (2012), Os Ícones de Andrei. Quatro diálogos com Tarkovsky, Coimbra, Centro de Investigação em Antropologia e Saúde.

Evangelho segundo João (2016), in Bíblia, vol. I: Os Quatro Evangelhos, Lisboa, Quetzal: 31I-4I2.

Evangelho segundo Lucas (2016), in Bíblia, vol. I: Os Quatro Evangelhos, Lisboa, Quetzal: 215-310.

Evangelho segundo Mateus (2016), in Bíblia, vol. I: Os Quatro Evangelhos, Lisboa, Quetzal: 51-155.

Faria, Daniel (2007), O Livro do Joaquim, Famalicão, Quasi.

Freud, Sigmund (1994), “Transitoriedade”, in Textos Essenciais sobre Literatura, Arte e Psicanálise, Mem Martins, Publicações Europa-América: 194-197 [1916].

Helder, Herberto (2009), Lugar, in Ofício Cantante. Poesia completa, Lisboa, Assírio \& Alvim: 125-182 [1962].

Lawrence, D. H. (1993), Apocalipse, Lisboa, Hiena [1930]. 
Llansol, Maria Gabriela (1996), Inquérito às Quatro Confidências. Diário III, Lisboa, Relógio d'Água.

Tarkovsky, Andrei (1979), Сталкер (Stalker), argumento de Andrei Tarkovsky, Arkadi e Boris Strugatski, a partir do romance de Arkadi e Boris Strugatski, Piquenique na Borda do Caminho; fotografia de Alexandre Knyazhinsky; com Alexandr Kaidanovsky, Alisa Frejndlikh, Anatoli Solonitsyn, Nikolai Grinko, Natasha Abramova; produção Mosfilm, União Soviética. 